ISSN: 2386-9658

\title{
¿Tú crees en Eva Braun?
}

\author{
DELFÍN ESTÉVEZ RODRÍGUEZ \\ eldelfinylared@hotmail.com
}

[Sala de conferencias. Sobre el fondo está proyectada una imagen de Dalí y Gala]

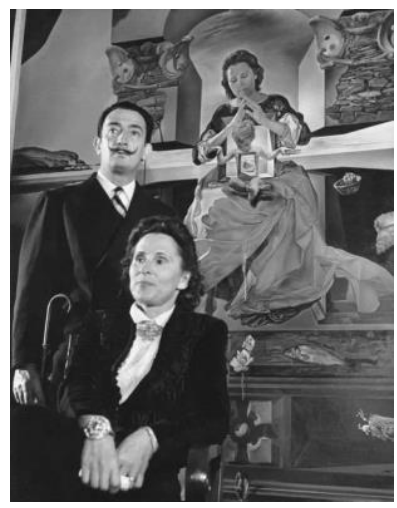

[La ponente sube al estrado, se sienta y bebe agua de una botella sacada de su bolso, ignorando el vaso y la jarra dispuestos sobre la mesa.]

Buenas tardes.

Mi nombre es Eva Braun, y antes de nada quiero dar las gracias al Instituto Cervantes por darme esta oportunidad para hablar sobre la apasionante relación entre dos de las figuras más destacadas del arte del s. XX: Salvador Dalí y su esposa Gala.

Antes de continuar, me adelanto a la pregunta que muchos de ustedes se están haciendo: Sí, han oído bien, mi nombre es Eva Braun, igual que... Bueno... Igual que la pareja de Adolf Hitler... [Esboza una sonrisa afable]... No importa... No pasa nada... Estoy acostumbrada a tener que explicarlo cada vez que digo mi nombre en cualquier sitio... Así que se lo explico en dos minutos. En el sur de España -en Andalucía-, y más concretamente en la provincia de Jaén, hay una ciudad que se llama La Carolina y a pesar de ser una ciudad española, muchos de sus habitantes tienen apellido alemán. El motivo es que, en España, a lo largo de los siglos, se han hecho grandes esfuerzos por repoblar aquellas tierras donde faltaba mano de obra y concretamente en mi provincia se instalaron centenares de trabajadores alemanes. Y como en algún lado tenían que vivir, construyeron La Carolina. 


\section{DELFín EsTÉVEZ}

De hecho, el nombre de la ciudad es La Carolina porque el rey que trajo a los alemanes fue Carlos III... Y por esa razón yo me apellido Braun... Que -por cierto- yo siempre pensé que era un apellido tan español como García, y si me enteré de que era alemán fue gracias a las bromas que tuve que soportar en el colegio, donde enseguida me bautizaron como la... Bueno, da igual... Ya se sabe que los niños son crueles por naturaleza.

Y tras este breve apunte autobiográfico, vamos a hablar de Gala y Dalí... [Cambia diapositiva.]

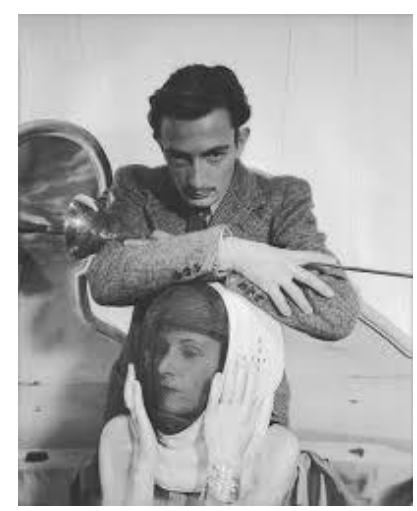

Ah, bueno, una última cosa que les va a resultar aún más curiosa. Yo me llamo Eva porque es el nombre de mi madre; en mi casa no se pretendía hacer ningún homenaje a nadie y durante mi infancia ni se me pasó por la cabeza que Eva Braun fuera el nombre de alguien importante: Eva Braun era... Yo. Punto. Bueno, pues hagan un esfuerzo de imaginación... Imaginen que de un día para otro descubren que ustedes se llaman igual que una de las personas más importantes de la Historia. Pues eso es lo que me paso a mí. Acababa de empezar la universidad cuando - de forma casual- tuve conocimiento de la historia de la otra Eva... Me quedé... Sin palabras... No sé cómo decírselo...

Fíjense, yo nunca había tenido ningún interés por la política ni por la historia, pero aquel descubrimiento me... No sé cómo decirlo... Me llegó al corazón. Hasta tal punto llegó mi curiosidad por mi compañera de nombre que ese mismo año dejé los estudios de Derecho y me matriculé en la facultad de Historia... [Pausa. Se levanta bruscamente y se acerca a la puerta, como si temiera que alguien la estuviera vigilando. Tras un instante, regresa y se acerca al público dispuesta a hacer una confidencia.]

Miren... Yo no debería hablar de esto... Porque yo he venido a hablar de otra cosa y, además, aunque les parezca extraño, he tenido bastantes problemas en el pasado por tocar este tema... Pero... Permítanme una sola pregunta... 
Permítanme... Porque esto es algo que me quema por dentro... ¿Alguno de ustedes se ha preguntado por qué Hitler... No se regodeó... No se deleitó... En la crueldad? Porque no lo hizo... Por más que lo pinten como el summum de la maldad... Hay unos hechos, y esos hechos son claros; la gran mayoría de las personas que perdieron la vida en los campos de trabajo fallecieron en cámaras de gas, lo cual -con perdón- es un modo bastante tranquilo de morir, si lo comparamos con las crueldades que hemos visto en otros lugares. Los condenados no tenían ocasión de experimentar ningún sufrimiento por la proximidad de la muerte: los introducían en las cámaras de gas, haciéndoles creer que iban a darse una ducha.... Pero permítanme ir al grano... Me gustaría que se cuestionaran algo ¿Por qué? ¿Por qué esa... No sé... Esa compasión? ¿Cuál pudo ser el motivo que influyó en la mente de Hitler para tener aquellos gestos de humanidad? ¿De verdad nadie se lo ha preguntado?... Pues yo sí... Y la respuesta siempre es la misma... La respuesta es Eva... ¿¿Quién si no?

Eva comprendió que había venido al mundo para llevar a cabo una misión extraordinaria... Y la cumplió hasta sus últimas consecuencias. Podría haber optado por una existencia mucho más confortable pero no lo hizo. Como todo el mundo sabe, Eva siempre fue libre de dejar a Hitler, pero eligió permanecer a su lado porque sabía que nadie más podría hacer aquel trabajo. Tal vez alguien piense que aquello no representaba ningún esfuerzo para ella. El que diga eso seguramente no sepa que, durante aquellos años, Eva trató de quitarse la vida al menos en dos ocasiones. No señor, no fue fácil, pero el trabajo de los grandes hombres y mujeres nunca es fácil.

He llegado a escuchar -fijense- que Eva era una joven alegre, pero "algo tonta". Bendito sea Dios. He aquí la prueba definitiva en favor de la grandeza de Eva: tan solo los seres más elevados son tomados por ingenuos. Por supuesto que era una joven alegre: Eva había sido bendecida con el don de la alegría, y la utilizó con absoluta destreza para hacer el bien: fue capaz de humanizar los sentimientos y las decisiones de un hombre que hubiera podido convertir Europa en un verdadero infierno.

Aquí de lo que estamos hablando es de un sacrificio. Estamos hablando de una mujer que, con apenas 33 años, renuncia a su propia felicidad y se sacrifica por todos nosotros. Su entrega en favor de sus semejantes... Fue de tal magnitud que nunca he encontrado las palabras para... Bueno... Ya les digo que para mí es algo... Para mí... No sé... Yo lo único que sé es que en mi vida hubo un antes y un después desde que descubrí que... Bueno, desde que descubrí a Eva Braun... Y, sobre todo, desde que se reveló ante mis ojos como el verdadero ángel del siglo XX... 


\section{DELFín EsTÉVEZ}

Bueno... No sé si estoy siendo clara: algunos de ustedes creerán en Dios, o en Buda, o en Krisna... Pues ¿quieren saber ustedes en quien creo yo? Yo creo en Eva Braun, si señor... Yo creo en Eva Braun. [Pausa. Oimos un sonido. Parece que ba recibido un mensaje en su teléfono móvil. Lo lee, inquieta.]

... Bueno, espero no haber molestado a nadie con lo que he dicho.... [Cambia la diapositiva y aparece una pintura de Dali.]

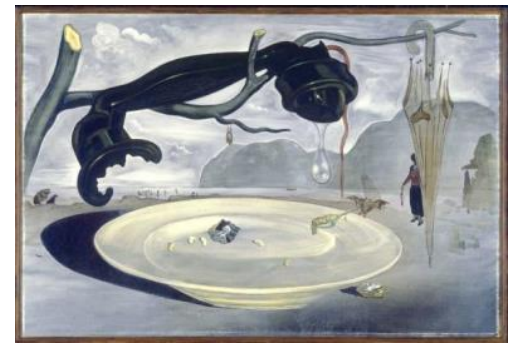

...Y aprovecho para dejar absolutamente claro que mi entrega hacia la figura y la obra de Eva Braun no supone de ningún modo una declaración de simpatía hacia su marido. Con su permiso, prefiero no entrar en detalles sobre lo que hizo Adolf Hitler. Lo único que diré -con el mayor de los respetos- es que a veces ser un soñador puede convertirse en el mayor pecado del mundo.

Volvamos a Dalí. [Cambia diapositiva.]

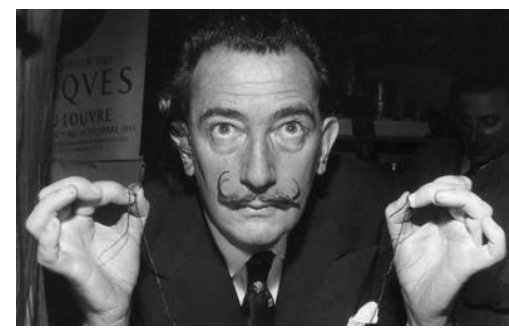

...Pero estarán de acuerdo conmigo en que ha habido otros soñadores que, estos sí, se han encontrado el viento a favor y han logrado cambiar el curso de la Historia. A esos sí, a esos los admiramos y les ponemos una estatua en medio de una plaza, y a los otros se los llama locos, dictadores y genocidas. Esto es así, nos guste o no. [Cambia diapositiva.] 
¿Tú crees en Eva Braun?

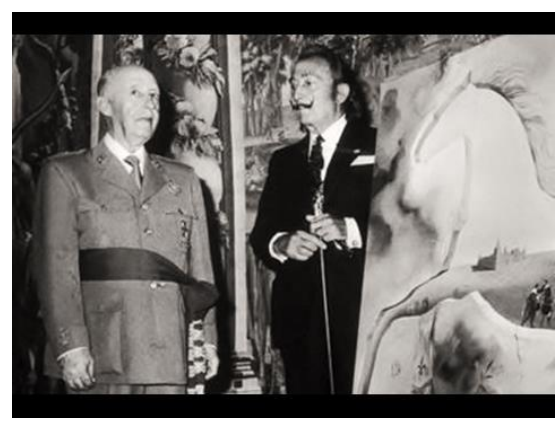

Pero insisto en que no quiero entrar en temas delicados... Lo que sí tengo que decir, porque lo he vivido en primera persona, es que a veces hay que pagar un alto precio por ser uno mismo... Aunque no se lo crean... Una gran parte de mi familia ha dejado de relacionarse conmigo por culpa de mis creencias... Por Eva Braun, digo... No les guardo rencor, lo importante es que ahora estoy más cerca de ser yo misma, y con eso tengo más que suficiente.

Eso sí, estaría bien que todos asumiéramos nuestras responsabilidades en lugar de clasificar al prójimo como bueno, malo o loco. [Se acerca de nuevo a la puerta, y tras asegurarse que no bay testigos inoportunos, regresa junto al público.]

$\mathrm{Y}$ si lo que resulta tan dificultoso es cuestionarse ciertas cosas... De las que nadie se atreve a hablar, yo les regalo gustosamente un par de preguntas a aquellos que las quieran oír ¿tan fáciles de engañar eran aquellos prisioneros cuando caminaban a las cámaras de gas? ¿de verdad pensaban que iban a ducharse? Yo diría más bien otra cosa... Con perdón... Yo diría que a nadie le apetece hablar de la cobardía y la ineptitud. Y otra cosa más ¿tan ignorantes éramos los europeos como para no saber a dónde iban aquellos trenes cargados de judíos?

Recuerdo a un empleado de los ferrocarriles alemanes que, en una entrevista grabada años después, aseguraba -con la mano en el corazón- que para él la palabra "Auschwitz" era tan solo el nombre de una estación donde se detenía su tren... ¿Qué clase de broma es esta? ¿Alguien puede creerse las palabras de ese maquinista? Por favor... Una cosa es la ignorancia y otra cosa es... Perdonen que les hable de esta forma, pero es que no puedo con estas cosas.

Llevamos setenta años removiendo la misma mie... coartada [pausa]: la ignorancia y el engaño. [Mira inquieta la puerta del auditorio, y cambia la diapositiva.] 


\section{DELFÍN ESTÉVEZ}

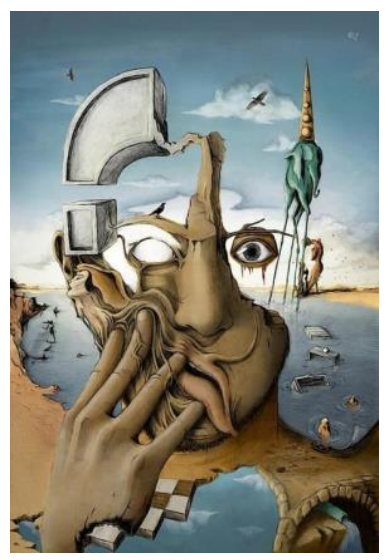

¿Por qué es tan difícil encontrar a gente con un pensamiento sano? ¿Alguien me puede decir por qué no puedo enaltecer a una de las personalidades más admirables del siglo pasado? La razón es muy sencilla: nadie nos ha educado para tener un pensamiento propio... Somos el resultado de una sociedad que nos obliga a clasificar a los grandes personajes como buenos o malos, y a Eva - por supuestola Historia oficial le ha puesto una etiqueta que dice que fue mujer malvada.

En fin... Saben a lo que me refiero cuando uso la palabra "etiqueta", ¿verdad? Una etiqueta es como una careta, pero al revés: en vez de ponértela tú para ocultar quién eres, te la ponen los demás para que a nadie le quede ninguna duda de lo que eres... Y si tu etiqueta indica que eres un bellaco... No hay nada que hacer... Mala suerte.

Perdónenme, pero yo no puedo estar de acuerdo con semejante monstruosidad.

¿A dónde vamos a llegar por este camino? ¿es tan difícil vivir sin recurrir a las etiquetas? De verdad... ¿Ustedes se creen que a mí me hace falta que venga un sabio a decirme si una persona es buena o es mala? La vida no es una novela ni una comedia barata. La vida es otra cosa, no sé el qué, pero no es una historia de buenos y malos. La vida no es una obra de teatro... Por favor... Yo odio el teatro, lo odio con todas mis fuerzas, llevo años sin pisar un teatro. Alguno de ustedes estará pensando "esta mujer está loca"... No, no se preocupen, no estoy loca: yo no odio el arte -solo faltaría...- $\mathrm{Al}$ contrario, soy una gran enamorada de la música, la pintura, el cine... Pero el teatro... ¿Cómo se lo explico?... A ver... Imagínense esta situación: yo voy a ver una función porque el tema de la obra me interesa. ¿Por qué voy a ir si no? Me siento en mi butaca y escucho con atención de la primera palabra a la última, y cuando cae el telón y por fin puedo reflexionar sobre aquel pedazo de vida, estalla a mi alrededor un escándalo de descerebrados 
haciendo chocar sus manos... ¿Pero esto qué es? ¿a quién pretendéis premiar? ¿Pensáis que alguien se puede sentir reconfortado por vuestras convulsiones?... $\mathrm{O}$, peor aún, ¿de verdad pensáis que el mundo necesita conocer vuestra opinión sobre la función?

No es fácil hablar de esto... Pero bueno... No sé... ¿'A ustedes les parece una locura?

Alguien me dijo que en este tema no se podía hacer nada... Que aquello formaba parte de la libertad individual de la gente... Ya... ¿Y qué pasa con mi libertad individual? ¿alguien se ha preguntado cómo me siento yo en esos momentos? ¿Y si yo no quiero unirme a la fiesta de los orangutanes? Pues no quiero ¿entienden? Pero al final -miren ustedes por donde- al final aplaudo, al final me rindo y aplaudo... Agacho la cabeza, me trago la rabia y aplaudo para evitar que me tomen por una tía rara. Entonces me salgo de mí misma y me observo desde fuera... Y me veo convertida en una esclava de la voluntad de los otros ¿Por qué me está pasando esto? Y mientras todos aquellos cavernícolas aplauden, me pregunto ¿̇en qué momento exacto los orangutanes me han tomado como prisionera? Y cuando veo que el público se pone en pie y grita "bravo"... Bueno... Es que cuando los orangutanes se alzan sobre sus patas traseras para seguir vociferando... Yo lo único que quiero es desaparecer del universo.

Llegados a este punto yo me niego en redondo a alzarme de mi butaca y me veo convertida en un cuerpo semihundido en medio de la tormenta. Ojo: un cuerpo semihundido pero digno.

Por fortuna todo tiene un límite, y el mío llegó en las Navidades de 1985. Aquella noche fui al teatro para olvidar las peleas con mis hermanos. Acudí sola y casi sin saber lo que iba a ver, y me encontré con una comedia absolutamente estúpida... Tan estúpida que no podía dejar de reír... Y entonces sucedió algo inesperado... No sé cómo explicarlo... A medida que notaba más y más cercano el final de la obra me fui contagiando de una sensación desconocida... Una mezcla de alegría y agradecimiento... Y en el preciso instante en que las luces se apagaron, explotó en mí ese mismo impulso que tanto había despreciado en mis semejantes... Sí, señores... Mis manos cobraron vida propia y empezaron a chocar entre sí llevadas por una energía arrolladora, y no solo eso, sino que -como animado por una fuerza superior- mi cuerpo se alzó de la butaca para seguir aplaudiendo desaforadamente. Sentía una mezcla de rabia y de euforia, no era dueña de mí misma, pero, desde luego, pocas veces me había sentido tan feliz.

$\mathrm{Y}$ así hubiera dejado pasar los minutos de no ser por aquel monstruoso susurro que comenzó a elevarse a mi alrededor: "que no ha terminado"... “¿Qué?”... "Que no ha terminado"... Sin detener mis aplausos posé la mirada en aquellas despreciables alimañas que ocupaban las butacas de mi alrededor... Lo que vi se 


\section{DELFín EsTÉVEZ}

me clavó como un cuchillo... Un ejército de bocas reclamándome silencio... Un clamor de cobardes censurando mi derecho a aplaudir con rabia. Por supuesto, yo no dejé de aplaudir, ni siquiera dejé de aplaudir cuando se decidieron a pedírmelo los mismísimos actores, ni tampoco mientras los acomodadores me sacaban en volandas por la puerta de emergencia.

Seguí aplaudiendo mientras bajaba por la avenida en dirección al tranvía, y aún me quedó energía y aliento para dedicar algún "bravo" a los viandantes de la Avenida Diagonal.

Jamás he vuelto a pisar un teatro, ni he permitido a nadie que me dé lecciones de "libertad individual". A mí, lecciones, ninguna... Porque aquella noche en Barcelona mis ganas de aplaudir fueron olímpicamente boicoteadas por un montón de [entre dientes] hijos de puta. Y allí nadie dio la cara por mí. Nadie levantó una mano por mí. [La creciente irritación de Eva es interrumpida por la intervención del técnico de cabina, que se acerca inquieto y susurra algo al oído a Eva, tras lo cual regresa a su puesto.]

Perdonen, ¿¿h?... Pero... ¿Qué hacemos...? Es decir... ¿Qué hago cuando la libertad individual de otra persona me molesta? Sí... ¿Qué hago?... No quiero volver al maldito tema de los aplausos, pero es que -no sé ustedes- pero yo me encuentro con este problema todos los días.

[La intervención del técnico no ha tranquilizado a Eva, en vista de lo cual desde cabina deciden tomar la iniciativa y cambiar de diapositiva. Eva, indignada por aquel motin, hace uso de su propio mando a distancia para regresar a la imagen anterior. Guerra de diapositivas entre Eva y el técnico. $]$

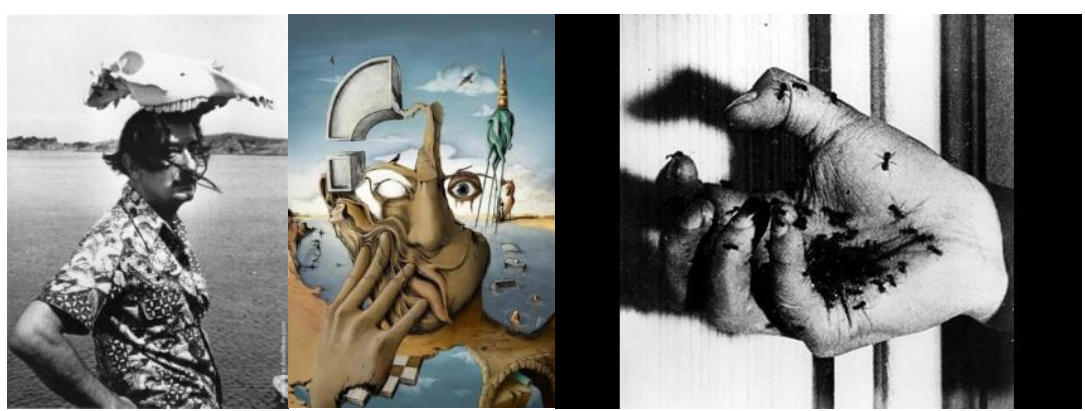

[Finalmente un trabajador de la sala pide a Eva que salga. Tras unos segundos, Eva regresa, cambiada.]

Disculpen. Hace unos minutos se me ha escapado un comentario que tal vez haya estado fuera de lugar. Les pido disculpas. Me refiero a una observación sobre 
los prisioneros que entraban en las cámaras de gas... Creo que he usado las palabras cobardía e ineptitud... Perdón... Quizás me he expresado mal.

No pretendía... Bueno... No volverá a suceder....

Es que ese tema en particular me pone muy nerviosa... En fin... Pero bueno, hemos quedado en que no vamos a volver a hablar de ello... Pero... No sé cómo decirles... De verdad... Me gustaría que me entendieran... [Cambia diapositiva.]

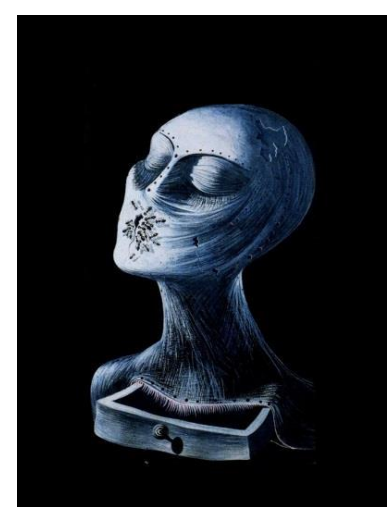

Me pasa exactamente lo mismo con las cucarachas... Vamos a ver... Yo sé que es absurdo culpar a las cucarachas por formar parte de la naturaleza, pero me pongo muy nerviosa cuando me las encuentro en casa... ¿A ustedes no les pasa? Bueno... Qué narices... Voy a ser completamente sincera... ¿Por qué no decirlo? Yo hablo con las cucarachas... Sí... Yo hablo con las cucarachas... Las veo meterse debajo de la lavadora y - se lo juro- con el mismo respeto que estoy empleando ahora con ustedes, me dirijo a ellas con esta voz [cambia la voq]... Así, suave... Y les digo: "no hagáis eso, por favor... Os estáis equivocando... No podemos pasarnos la vida huyendo de nuestras responsabilidades". Desgraciadamente, mis palabras no suelen dar resultado y ellas siguen corriendo hacia la oscuridad... [Cuando parece que ha terminado, vuelve a la carga.] Pero yo insisto "no, por favor ¿no os dais cuenta de que esto es peor para vosotras?"

Por si alguien no lo ve claramente, lo que espero de las cucarachas es que asuman sus responsabilidades... Nada más que eso. Insisto... Una cucaracha no tiene la culpa por ser lo que es, pero sí tiene una gran responsabilidad por hacer lo que hace... Las cosas no se solucionan pensando "pobrecita... Bastante tiene con lo que tiene"... ¿Saben cómo se llama eso? Eso se llama compasión mal entendida, y eso es algo que hace mucho daño. Hablemos de solidaridad, si no les importa. Llevo años defendiendo la solidaridad frente a la compasión. Me explico: hazme ver que no tienes miedo al peligro, demuéstrame que estás dispuesta a 


\section{DELFÍN ESTÉVEZ}

todo: entonces te respeto, porque cuando dos voluntades comparten el mismo coraje, puede haber solidaridad. Pero yo no puedo respetarte ni ser compasiva si todo lo que tienes que ofrecer es cobardía, debilidad y temor. Ahí no... No señor... Compasión ninguna.

La última cucaracha a la que le planteé este tema, en vez de darme las gracias, se hizo la sorda y trató de meterse detrás de la librería... Bueno... Ese día sí que perdí los papeles, me pillé un sofocón "pero ¿qué te pasa? ¿es que no tienes orgullo?... Da la cara, jodida..." Ay, madre, que cabreo me pillé... Me fui a por el bote de spray que tengo en el baño y "fshhhhh"... La gaseé a ella y a todas sus amigas... Fue un pronto ¿vale?... A la mañana siguiente, cuando me desperté... Aquello parecía una película de terror... La alfombra del salón apareció cubierta de pequeños cadáveres con los rostros desencajados... Bueno, en realidad no les veía el rostro, pero me lo imaginaba.

Bueno, no se lo van a creer, pero una de las cucarachas sobrevivió al gas. Se había refugiado en el cubilete de los lápices y el veneno no la alcanzó. Cuando la encontré estaba desorientada y trataba de escalar por una pluma estilográfica... La pobre... El caso es que me la llevé a otra habitación para que no viera lo que había sucedido con sus hermanas y hablé con ella cinco minutos - “¿me permites que te diga una cosa?" le digo- "tu problema es un problema de actitud... No se puede ir así por la vida... ¿Cómo quieres que te respete si tú no te respetas a ti misma?... Mira... Una persona puede ser holgazana, caradura, estirada... Pero ¿̇sabes lo que no se puede ser? No se puede ser miserable, porque si tú eliges ser miserable... ¿Qué puedo hacer yo? lo único que puedo hacer es odiarte... ¿Tú quieres eso? No ¿verdad? Vamos a ver ¿tú por qué huyes cuando enciendo la luz? ¿crees que no te veo? Te veo, y lo que es peor, veo tu cobardía, y te conviene saber algo... Los seres humanos -no me preguntes por qué- odiamos todo lo que huele a cobardía... ¿ $\mathrm{O}$ qué te pensabas? ¿Que odiábamos a las cucarachas por capricho? Os odiamos porque renunciáis a la lucha y preferís correr a vuestro agujero... Y para el ser humano no existe nada tan sagrado como un buen combate a muerte. Piensa en las ratas, a las ratas se las odia, es verdad, pero sobre todo se las teme, ¿por qué? porque una rata está dispuesta a atacarte, y eso la ennoblece. Si tú no te haces respetar, nadie lo va a hacer por ti. Correr -insistí- correr nunca es una buena idea, porque cuando alguien huye se convierte en culpable.

No estoy segura de si comprendió la lógica de lo que le estaba diciendo, pero le puse un último ejemplo, le hablé de las tortugas -tenemos mucho que aprender de las tortugas-... Le dije que las tortugas eran criaturas muy queridas entre las personas, y precisamente eran queridas por el hecho de que -pasase lo que pasase- nunca corrían. Se lo expliqué de la mejor manera que pude: "tienes que darte cuenta de que una tortuga es honesta y eso se ve enseguida, si yo me acerco 
con un martillo y la reviento, no huye, no se esconde ni se va a planear su venganza. Tú la revientas y ella se aguanta. Los dos vais de frente". No vi a la cucaracha muy convencida - de hecho, seguía intentando salir del cubilete de los lápices- así que tuve que ponerme firme: "¡Ya!... ¡Se acabó!... Es tiempo de cambiar... Es tiempo de aprender a tener orgullo... Hazme caso, que te irá bien... No os engañéis... Aquí ya no hay lugar para los miserables ni para los cobardes...”. [Con un sencillo gesto de la mano, Eva nos da a entender que también esta cucaracha termina gaseada.] ¿ Os digo un secreto? Nada molesta más a los fuertes que descubrir que los miserables los toman por gilipollas. Y que no me vengan con que a los débiles no les queda otra alternativa que conspirar. Siempre hay otra alternativa, siempre nos queda el ejemplo de la tortuga.

Todo eso le dije a la cucaracha en un momento. Algún día tengo que profundizar en este tema de las cucarachas. Confieso que siempre he sentido mucha más curiosidad por las cosas que me inspiran odio que por las que me inspiran amor... Me pasa desde siempre... Especialmente me siento fascinada por aquellas cosas que despiertan un profundo odio sin ningún motivo... ¿No les parece sorprendente?

Disculpen, no me quiero desviar más... Pero estarán de acuerdo conmigo en que la vida es un lugar extraño y salvaje... [Cambia diapositiva.]

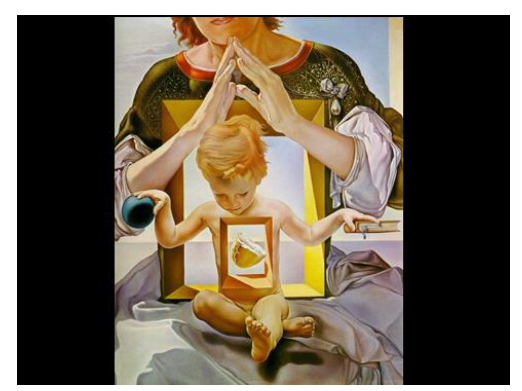

Bueno, vamos con Dalí, que yo no estoy aquí para mostrar el camino a nadie... Bien es cierto que yo he tenido la gran suerte de encontrar mi camino junto a Eva... Y... De verdad... Deseo de todo corazón que cada uno de ustedes encuentre a su propia Eva Braun -pónganle el nombre que quieran-. Pero, sobre todo, sean fuertes y no se dejen vencer por la fatiga y la desilusión. Yo ya he comprobado que los seres humanos somos capaces de lo mejor y lo peor, y de verdad que yo misma me pregunto de donde salen ciertos individuos que se llaman a sí mismos personas. Pues les diré algo: del mismo modo que en un bosque hay diferentes tipos de madera, así sucede con las personas: hay madera buena y madera mala. Punto. No le den más vueltas. 


\section{DELFín EsTÉVEZ}

Fíjense: alguien me contó que, durante el último invierno en el campo de concentración de Auschwitz, un padre y su hijo se encontraron un pedazo de pan junto a los vagones del tren. En vez de comérselo inmediatamente, lo partieron en dos mitades y lo escondieron bajo sus respectivos colchones. Pero el hijo estaba muy enfermo y al día siguiente amaneció muerto. Al recibir la noticia, el padre acudió junto al cadáver de su hijo y se quedó mirando sin derramar una sola lágrima. Esperó a que todos se fueran y cuando pensó que nadie lo veía, buscó el pedazo de pan bajo el colchón... Entonces descubrió que le habían robado el pan a su hijo y en ese momento empezó a llorar. No sé... Díganme ustedes si eso es ser un padre... Líbreme el señor de juzgar a otra persona, pero ¿qué tenía ese hombre dentro del pecho? ¿un corazón o una piedra?... Pues eso... Que en el bosque hay madera buena y madera mala... Perdón ¿eh? [Cambia diapositiva.]

Salvador Dalí conoció a Gala en el verano de 1929, cuando un grupo de surrealistas franceses decidió viajar a la casa del pintor en la costa de Cadaqués...

OSCURO 